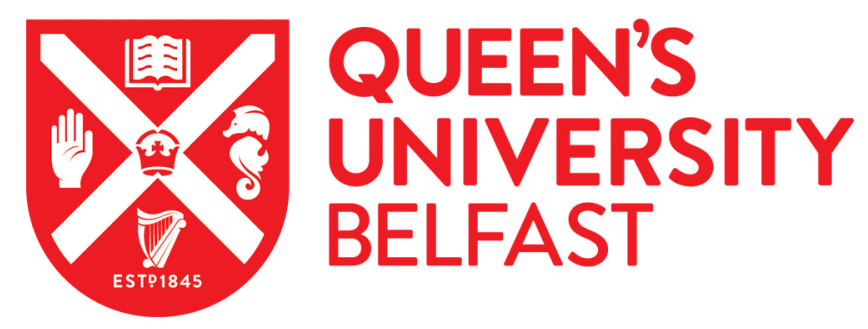

\title{
Mechanism of Alizarin Red S and Methylene Blue Biosorption onto Olive Stone: Isotherm study in Single and Binary Systems
}

\begin{abstract}
Albadarin, A. B., \& Mangwandi, C. (2015). Mechanism of Alizarin Red S and Methylene Blue Biosorption onto Olive Stone: Isotherm study in Single and Binary Systems. Journal of Environmental Management, 164, 86-93. https://doi.org/10.1016/j.jenvman.2015.08.040
\end{abstract}

Published in:

Journal of Environmental Management

Document Version:

Peer reviewed version

Queen's University Belfast - Research Portal:

Link to publication record in Queen's University Belfast Research Portal

Publisher rights

(c) 2015 Elsevier Ltd. This manuscript version is made available under the CC-BY-NC-ND 4.0 license http://creativecommons.org/licenses/by$\mathrm{nc}-\mathrm{nd} / 4.0 /$ which permits distribution and reproduction for non-commercial purposes, provided the author and source are cited.

\section{General rights}

Copyright for the publications made accessible via the Queen's University Belfast Research Portal is retained by the author(s) and / or other copyright owners and it is a condition of accessing these publications that users recognise and abide by the legal requirements associated with these rights.

Take down policy

The Research Portal is Queen's institutional repository that provides access to Queen's research output. Every effort has been made to ensure that content in the Research Portal does not infringe any person's rights, or applicable UK laws. If you discover content in the Research Portal that you believe breaches copyright or violates any law, please contact openaccess@qub.ac.uk. 


\title{
Mechanism of Alizarin Red S and Methylene Blue Biosorption onto Olive Stone: Isotherm study in Single and Binary Systems
}

\author{
Ahmad B. Albadarin ${ }^{1,2 *}$, Chirangano Mangwandi ${ }^{2}$ \\ ${ }^{1}$ Department of Chemical and Environmental Sciences, Materials \& Surface Science Institute, \\ University of Limerick, Ireland. \\ ${ }^{2}$ School of Chemistry and Chemical Engineering, Queen's University Belfast, Belfast BT9 5AG, \\ Northern Ireland UK.
}

\section{ABSTRACT}

The biosorption process of anionic dye Alizarin Red S (ARS) and cationic dye methylene blue (MB) as a function of contact time, initial concentration and solution $\mathrm{pH}$ onto olive stone (OS) biomass has been investigated. Equilibrium biosorption isotherms in single and binary systems and kinetics in batch mode were also examined. The kinetic data of the two dyes were better described by the pseudo second-order model. At low concentration, ARS dye appeared to follow a two-step diffusion process, while MB dye followed a three-step diffusion process. The biosorption experimental data for ARS and MB dyes were well suited to the Redlich-Peterson isotherm. The maximum biosorption of ARS dye, $q_{\max }=16.10 \mathrm{mg} / \mathrm{g}$, was obtained at $\mathrm{pH} 3.28$ and the maximum biosorption of $\mathrm{MB}$ dye, $q_{\max }=13.20 \mathrm{mg} / \mathrm{g}$, was observed at basic $\mathrm{pH}$ values. In the binary system, it was indicated that the MB dye diffuses firstly inside the biosorbent particle and occupies the biosorption sites forming a monodentate complex and then the ARS dye enters and can only bind to untaken sites; forms a tridentate complex with OS active sites.

Keywords: Anionic Dye; Alizarin Red S; Cationic Dye; Methylene Blue; Dyes Removal; Biosorption; Olive Stone.

\footnotetext{
*Corresponding author: Dr Ahmad B. Albadarin: Ahmad.B.Albadarin@ul.ie. University of Limerick. Tel: +44 746080 5982; fax: +353 (0) 61202568.
} 


\section{Introduction}

Large amounts of dye contaminated wastewater are being released yearly from leather, cosmetics, pharmaceutical, plastics and textile industries, and results in an impending hazard to human health and the ecosystem (Cao et al., 2014; Semeraro et al., 2015). The existence of such dyes in receiving water bodies is undesirable as they cut off sunlight and reduce photosynthetic activities of autotrophic organisms (Albadarin et al., 2014). The problem is escalating because these dyes are stable and non-biodegradable (Gorgulu Ari and Celik, 2013); dyes are designed to hold colour on various materials and resist water, soap and oxidizing agents (Khataee et al., 2013). Consequently, the removal of dyes from industrial effluents is a challenging problem and it is essential to optimize dye-removal methods. The low efficiency, high cost, and in some cases, the production of toxic by-products make some physical and chemical approaches such as filtration, coagulation, photocatalytic degradation and advanced oxidation processes impractical and expensive to operate (Kabbout and Taha, 2014). Biosorption has been proven as an effective and cheap process, especially when using biowastes and agricultural by-products as the biosorbent (Albadarin et al., 2011). The search for low-cost and locally available waste materials for the biosorption of dyes continues and, recently, has been extensively accelerated (Abdolali et al., 2014; Guerrero-Coronilla et al., 2015; Guo et al., 2014; Magriotis et al., 2014; Wang et al., 2015). Olive crops cover a global cultivated area of approx. 10 million hectares. One main by-product produced in olive oil extraction and pitted table olive manufacture is olive stone. In Spain during the 2009/2010 season, olive oil and table olives world production result in 0.17 and 2.10 million tons, respectively (The Int. Olive Coun. 2012). This by-product is mainly turned into bioethanol or directly burnt to produce energy (Cuevas et al., 2015; Valentina Hernández et al., 2014). Using raw olive stones as biosorbent is another economic and environmental alternative (Ronda et al., 2013). This offers the olive processing industry an opportunity to make valuable use of the huge quantities of olive stones generated every year. 
Hence, olives stone (OS) was employed in this study for the biosorption of some dyes. Among the hazardous dyes, Alizarin Red S (ARS) and Methylene Blue (MB) are prime contaminants in the environment, and hence, these were selected as model dye systems. Alizarin Red S is a water soluble anthraquinone dye, is used extensively in the textile industry as a staining agent. It is considered to be one of the most recalcitrant and durable pollutants (Sun et al., 2011). This is due to its complex structures of aromatic rings that afford high optical and physicochemical stability (Fu et al., 2011). Methylene Blue is a cationic thiazine dye commonly used in various industrial applications due to its high adsorption ability. It is not regarded as highly toxic, though, it may cause several harmful effects, such as: difficult breathing on inhalation, gastritis, severe headache, painful micturition, and methemoglobinemia-like syndromes if large amounts are swallowed (Bhattacharyya and Sharma, 2005). The studies dealing with the removal of Alizarin Red S using raw biosorbents are scarce. However, previous studies on the removal of ARS onto activated materials showed that adsorption processes are very promising for pollution control (Fu et al., 2011; Zhang et al., 2001). For instant, a small amount of gold nanoparticles loaded on activated carbon $(0.015 \mathrm{~g})$ combined with ultrasound device achieved a high adsorption capacity (123.4 mg/g) in 5 min (Roosta et al., 2014). On the other hand, methylene blue biosorption has been investigated widely though the removal mechanism in binary systems has not yet been clearly understood. The main objectives of this study are to investigate: (i) the chemistry and the mechanism of ARS and MB biosorption onto olive stone and the type of OS-ARS, -MB interfaces occurring; (ii) the biosorption equilibrium and kinetic experimental data required for the design and operation of column reactors; (iii) the simultaneous biosorption isotherm of the two dyes in binary systems.

\section{Materials and Methods}

\subsection{Olive stone (OS) biomass}

The olive stones were crushed and 1000-355 $\mu \mathrm{m}$ fraction was chosen for the characterization 
and biosorption experiments without any pre-treatment. The biomass was washed a number of times with boiled water and finally with distilled water to remove any adhering dirt, and dried at $110^{\circ} \mathrm{C}$ for 24 hrs. Full and comprehensive characterization of OS can be found in a previous investigation (Blázquez et al., 2014). However, fourier transform infrared spectroscopy and scanning electron microscopy were employed to characterize the OS before and after ARS and MB biosorption. The FT-IR analyses for olive stones surfaces before and after ARS and MB biosorption were tested using the $\mathrm{KBr}$ pressed disc technique using a Perkin Elmer Spectrum 100 within the range of $400-4000 \mathrm{~cm}^{-1}$. For the SEM analysis, OS samples were coated with gold and vacuumed (5-10 min) for electron reflection prior to analysis on a JEOL-JSM 6400 scanning microscope. The samples used for the FT-IR and SEM analysis were collected from the $\mathrm{pH}$ effect experiment (optimum $\mathrm{pH}$ ).

\subsection{Procedures}

Alizarin Red S (342.2 g/mol) and Methylene Blue (319.8 g/mol) were purchased from Sigma Aldrich, UK. All chemical reagents were of analytical grades. Synthetic dye solutions used in the experiments were prepared with distilled water (resistivity $18.24 \Omega \mathrm{cm}$ ). Concentrations were measured using a UV-VIS spectrophotometer (Perkin Elmer LAMBDA 25, UK) at a maximum wavelength $\lambda_{\max }=668 \mathrm{~nm}$ for MB (Albadarin et al., 2014). Measurement of ARS concentration was carried out at $\lambda_{\max }=425-514 \mathrm{~nm}$ (Roosta et al., 2014) to minimize the $\mathrm{pH}$ effect on ARS concentration determination. It is known that, depending on the isosbestic point, ARS will change colour i.e. pale yellow at $\mathrm{pH}=2$; yellow orange at $\mathrm{pH}=3-4.9$; red at $\mathrm{pH}=$ 6.2-9 and violet at $\mathrm{pH}=11$ (Olivier Thomas and Burgess, 2007). The experiments of ARS and MB biosorption from aqueous solutions were carried out in a series of $50 \mathrm{~cm}^{3}$ glass jars; samples were regularly shaken (mechanical shaker, GerhardT type LS 5) at $100 \mathrm{rpm}$ and $20^{\circ} \mathrm{C}$ for 72 hrs to ensure reaching the equilibrium. The effect of initial solution $\mathrm{pH}$ on the removal of ARS and MB was examined in the range of 2-9, containing $25 \mathrm{~cm}^{3}$ of dye solution with $C_{\mathrm{o}}$ of 110 
$\mathrm{mg} / \mathrm{dm}^{3}$ and biomass dosage of $5.0 \mathrm{~g} / \mathrm{dm}^{3}$. The $\mathrm{pH}$ was altered using $0.1 \mathrm{M} \mathrm{HCl}$ or $0.1 \mathrm{M} \mathrm{NaOH}$. The same procedures were employed to investigate the effect of contact time and biosorption isotherms. The initial concentrations ranging from 30 to $205 \mathrm{mg} / \mathrm{dm}^{3}$ for ARS and MB were employed for the contact time experiment. For the biosorption isotherm studies in single and binary systems, $C_{\mathrm{o}}=5-105 \mathrm{mg} / \mathrm{dm}^{3}$ for ARS and MB were used. The isotherm studies in binary system were investigated at $\mathrm{pH} 3.4$ and 7.2. ARS and MB uptake, $q(\mathrm{mg} / \mathrm{g})$, and percentage of removal (\%) were calculated according to Eq. (1) and (2), respectively:

$q=\left[\frac{C_{o}-C_{e}}{M}\right] \times V$

The percentage removal $=\left[1-\frac{C_{e}}{C_{o}}\right] \times 100 \%$

where $C_{\mathrm{o}}$ and $C_{\mathrm{e}}$ are the initial and equilibrium concentrations of ARS and $\mathrm{MB}$ in $\mathrm{mg} / \mathrm{dm}{ }^{3}, M$ is the amount of dry biomass in grams and $V$ is the volume of the ARS/MB solution in $\mathrm{dm}^{3}$.

\section{Results and Discussion}

\subsection{Effect of contact time and initial dye concentration}

The effect of contact time on the biosorption capacity of OS for ARS and MB was studied at 
five different initial dye concentrations as revealed in Table 1. As expected, the biosorption capacity of OS increased with an increase in the initial dye concentrations. The ARS removal decreased from $85 \%$ to $50 \%$ as the ARS concentration was increased from 32 to $190 \mathrm{mg} / \mathrm{dm}^{3}$. While the MB removal decreased from $75 \%$ to $40 \%$ when the dye concentration increased from 30 to $205 \mathrm{mg} / \mathrm{dm}^{3}$. Figure 1 shows that the biosorption at various concentrations is fast in the initial stages and steadily decreases with the progress of biosorption until the equilibrium is reached. The difference in the biosorbed concentration of ARS and MB at equilibrium $\left(q_{\mathrm{e}}\right)$ and at time $t\left(q_{\mathrm{t}}\right)$ provides the key driving force to overcome all mass transfer resistances of the dye between the aqueous and solid phases (Liao et al., 2012).

\subsection{Kinetic modelling}

In the current study, the pseudo first-order model (Lagergren, 1898), pseudo second-order model (Ho and McKay, 1999), Intraparticle diffusion model (Weber and Morris, 1963) and Boyd kinetic model (Boyd et al., 1947a) were tested.

3.2.1. Pseudo first- and second-order kinetic models

The pseudo first-order model equation is given as follow:

$$
q_{t}=q_{e}\left(1-e^{-k_{1} t}\right)
$$

The pseudo second-order equation is given as;

$$
q_{t}=\frac{k_{2} q_{e}^{2}}{\left(1+k_{2} q_{e} t\right)} t
$$

where $k_{1}(1 / \mathrm{min})$ and $k_{2}$ (g/mg $\left.\mathrm{min}\right)$ are the rate constants for first- and second-order models. Table 1 summarizes the parameters of the pseudo first- and second-order kinetic models for ARS and MB biosorption onto OS. The highest $R^{2}$ values and well closer calculated $q_{\text {e,cal }}$ to those acquired by experiments, $q_{\mathrm{e}, \exp }$, confirmed that the biosorption process for both dyes is best described by the pseudo-second-order equation (Figure 1). The above conclusion reveals 
that the biosorption is a chemical process and the dye uptake capacity is proportional to the number of active sites (Glocheux et al., 2013; Weifeng Liu et al., 2011). Also, in Table 1, the nonlinear relations between the initial concentrations, $C_{0}$, of the dye and the rate constant, $k_{1}$, implies that mechanisms such as ion exchange and chelation are involved in the biosorption process. The decrease in rate constant, $k_{2}$, of the second-order model is attributable to the competition between higher levels of dye molecules (Albadarin et al., 2012; Albadarin et al., 2014). 
2 The intraparticle diffusion model was employed in order to distinguish the different resistances

3 to diffusion of ARS and MB onto olive stone. The model links the pollutant adsorbed at a given

4 time with the time $t$ following the Equation (5):

$5 \quad q_{t}=k_{d i} t^{0.5}+C_{d i}$

$6 k_{d i}$, the intraparticle diffusion rate is constant and expressed in $\mathrm{mg} / \mathrm{g} \cdot \mathrm{h}^{0.5}$ where $i$ represents the

7 diffusion phase number; $C_{d i}$ is proportional to the boundary layer thickness.

8 It can be seen in Table 2 that MB diffuses faster than ARS at low and high concentration. The 9 plot of $q_{t}$ versus $t^{0.5}$ is linear when the intraparticle diffusion is the main resistance step in the 10 experimental conditions. In this study, several regions were observed for the diffusion of ARS and $\mathrm{MB}$ in the porous olive stone materials; none of the plots passed through the origin $\left(C_{d i} \neq\right.$ 0) (see supplementary data: SD1). The values of intercept increased when the initial dye concentration was increased; $C_{d i}$ values give an idea about the boundary layer thickness; the larger the intercept, the greater is the boundary layer effect (values not shown here). The presence of different linear regions in the plot of $q_{t}$ versus $t^{0.5}$ implies that the intraparticles diffusion is not the only operative mechanism and that the biosorption kinetics of dyes on OS was controlled by both surface and intraparticle diffusion processes. At low concentration, the difference is more obvious and MB followed a three-step diffusion process while ARS seems to follow a two-step diffusion process. The difference in diffusion steps may be related to the molecular mass i.e. the higher the molecular mass, the slower the rate of diffusion. The higher charge density of MB compared to ARS enables a faster diffusion in OS biomass. In terms of diffusion parameters, the difference between ARS and MB biosorption is clearly observed for the first intraparticle diffusion step. The diffusion coefficients for MB biosorption are more than double

24 those for ARS biosorption (Table 2). The correlating coefficients, $R^{2}$, reported in Table 2 for 25 the intraparticle diffusion kinetic model are generally lower than that of the pseudo second- 
order kinetic for the biosorption of ARS and MB onto OS. These findings further confirm that the pseudo second-order mechanism is dominant and the overall rate of biosorption process is controlled by several portions.

\subsubsection{Boyd kinetic model}

The Boyd kinetic model was employed to confirm the actual rate-controlling step involved in the ARS and MB biosorption onto the OS. The Boyd kinetic equations are defined as (Boyd et al., 1947b):

$33 \quad F=1-\left(\frac{6}{\pi^{2}}\right) \exp (-B t) ; \quad$ where $F=q_{\mathrm{t}} / q_{\mathrm{e}}$

$B \times t=-0.4977-\ln (1-F)$

If a plot $B t$ versus $t$ is a straight line passing through the origin, it indicates a particle diffusion mechanism; contrarily, film-diffusion or chemical reaction control the adsorption rate. The plots (not shown here) revealed that the experimental data for both dyes do not follow the Boyd model and therefore particle diffusion does not control the rate of the biosorption process. Once again, this suggests that film-diffusion or chemical reaction controls the rate of biosorption. The biosorption systems were, in general, controlled by chemisorption including valence forces as covalent bonds/ion exchange between the adsorbent and dye molecules until the surface active sites were fully occupied. After that, dye molecules diffused into the biosorbent for further interactions (Tavlieva et al., 2013).

\section{3. $\mathrm{pH}$ effect}

The solution $\mathrm{pH}$ plays a significant role in the chemistry of both the OS biomass and dye molecules, and has a major effect on electrostatic charges that are imparted by ionized dye molecules. As illustrated in Figure 2, the removal of ARS and MB from aqueous solution is greatly dependent on the $\mathrm{pH}$ of the solution, and various functional groups such as hydroxyl, 

following a typical anionic adsorption behaviour (Silvina Pirillo et al., 2009). For the anionic dye, ARS, the adsorption capacity decreased from 14.31 to $0.662 \mathrm{mg} / \mathrm{g}$ when the $\mathrm{pH}$ increased from 3.28 to 8.16 . This is predominantly attributed to the deprotonation of the biosorbent surface and the presence of excess $\mathrm{OH}^{-}$ions competing with ARS molecules, which exist mainly in a monoanionic form (Olivier Thomas and Burgess, 2007). On the other hand, opposite trends were observed for cationic dye, MB. The amount of MB biosorbed increased with an increase in the $\mathrm{pH}$ of the $\mathrm{MB}$ solution; the maximum adsorption capacity of $\mathrm{MB}$ was $11.35 \mathrm{mg} / \mathrm{g}$, observed at $\mathrm{pH}$ 7.2. The point of zero charge of the olive stone biomass has been previously determined as 5.17 (Ronda et al., 2013). Therefore, these trends could also be well explained by the electrostatic interaction between the negatively charged surfaces of the biosorbent, at $\mathrm{pH}>\mathrm{pH}$ PzC, and the cationic dye (Galán et al., 2013). The results are in agreement with previous studies in which maximum biosorption of anionic dyes were observed at $\mathrm{pH}$ below 5, and the optimal removal of cationic dyes reported at basic $\mathrm{pH}$ values (Peng et al., 2014). It is worth noting that during/after dyes biosorption, the $\mathrm{pH}$ of the dye solution changed and this is a strong indication of a dye-hydrogen ion exchange and complexation processes. The amount of dye biosorbed, $\mathrm{mmol} / \mathrm{g}$, was calculated and compared to the number of $\mathrm{H}+$ ions released/adsorbed. The molar ratio of the biosorbed dye to released/adsorbed $\mathrm{H}+$ ions was 2.926 and 1.014 for ARS and MB, respectively.

\subsection{Isotherm experiments}

\subsubsection{Single systems}

Figure 3 shows the equilibrium isotherms of ARS and MB dyes onto OS biosorbent. Langmuir, Freundlich, Redlich-Peterson and Temkin isotherms were applied to the experimental data using non-linear regression in SigmaPlot Version 11 and the summary of the fits is presented 
for describing the biosorption of MB onto OS. For the ARS and MB dye, the Redlich-Peterson isotherm $\left(R^{2}=0.994\right.$ and $\left.R^{2}=0.998\right)$ gives the best description of the experimental data (Temkin and Levich, 1946). For MB biosorption, the value of $\beta$ obtained using the RedlichPeterson isotherm was close to unity (1.101), indicating that the isotherm is approaching the Langmuir rather than the Freundlich isotherm from (Redlich and Peterson, 1959). Also, the good fit of $\mathrm{MB}$ experimental equilibrium data to the Langmuir isotherm indicates the monolayer coverage and chemisorption of MB onto OS. According to Table 3, the olive stone has the monolayer Langmuir biosorption capacities of 16.10 and $13.20 \mathrm{mg} / \mathrm{g}$ for ARS and MB, respectively. At the high $C_{0}$ values used in this study, ion exchange sites and functional groups are more significant than the surface area $\left(0.16 \mathrm{~m}^{2} / \mathrm{g}\right.$ (Blázquez et al., 2014)) for biosorption, where chemical precipitation of the dye anions/ cations may play a dominant role in the dye removal. This may explain the high biosorption capacities despite the relatively small surface area of OS. The value of $1 / n$ obtained from the Freundlich isotherm for ARS was 0.457 and 0.426 for MB, which shows that the biosorption of ARS and MB onto OS is favourable (Albadarin et al., 2012). The slightly higher value of $K_{\mathrm{F}}$ for ARS dye indicates that OS possesses a higher biosorption capacity for ARS compared to MB dye. Table 4 provides a comparison between the biosorption capacities of ARS and MB dyes with earlier studies (Ai et al., 2011; Albadarin et al., 2014; Banat et al., 2003; Fu et al., 2011; Ghaedi et al., 2011; Gürses et al., 2006; Janoš et al., 2003; Wu et al., 2004). Keeping in mind that the olive stone used here is cheap, was used without any treatment and required very little preparation, the biosorption capacities for ARS and MB onto OS are very similar to those of alternative materials from earlier investigations.

\subsubsection{Binary systems}

The ARS and MB dyes used in this study have very similar isotherms; ARS and MB structures contain three benzene rings in a linear structure with no side chain. Ignoring the molecular 
100 charge, this suggests that in the case of competitive biosorption between the dyes, the process

101 can be considered as a single-component biosorption of a pseudo-component with properties

102 between the properties of the real components (Wouter Delée et al., 1998). Hence, the next

103 step of the present work was to discuss the simultaneous biosorption isotherm of two dyes at

104 their optimum $\mathrm{pH}$ (3.4 and 7.2).

105 The amount of dye biosorbed was determined and compared to that for the single system so as

106 to investigate the competitive character of the interaction between the two dyes. In Figure 4,

107 the curve for the binary dye solution at $\mathrm{pH}=7.2$ is almost identical to the sum of the curves for

108 the single-components. The above observations reveal that there is very limited competition

109 between the two components examined here. However, this competition can be detected and

110 this explains why the total adsorbed quantity of single-dyes is larger than a mixture of the two

111 components with the same concentration. This demonstrates that there is an abundant number

112 of active sites by which the two dyes can be sequestrated and for which they will, to some

113 extent, compete for if co-existing in a multicomponent systems.

114 Furthermore, it can be concluded that when in the binary system ( $\mathrm{pH}=7.2)$, the MB dye is first

115 to penetrate the biosorbent particle and to occupy the biosorption sites. Then, the ARS dye

116 enters and can only bind to untaken sites in an irreversible equilibrium scenario (George Z

117 Kyzas et al., 2013) (Figure 4). If the above assumption is correct, the MB positive molecules

118 may influence the biosorption of ARS negative molecules by providing a positively charged

119 phase and consequently decreasing the repulsion between the ARS molecules and enhance the

120 biosorption affinity. The binary system at $\mathrm{pH}=3.4$ seems to lower the amount of dyes

121 biosorbed. This can be due to the high completion between the hydrogen ions and the MB

122 molecules. However, this needs further investigation and will be considered for future work.

123 3.5. FT-IR and SEM analysis

124 Olive stone is a lignocellulosic material, with hemicellulose, cellulose and lignin as main 
components. The FT-IR spectrum for OS biomass in Figure 5 is very similar to those reported

126 for other biomasses such as tea waste and date stone (Albadarin et al., 2013). Peaks were

127 detected around 3430 and $2920 \mathrm{~cm}^{-1}$ and can be attributed to $-\mathrm{NH}_{2},-\mathrm{OH}$ groups and $-\mathrm{CH}$

128 stretching, respectively. Whereas $>\mathrm{C}=\mathrm{O}$ stretching vibration, symmetric bending of $\mathrm{CH}_{3}$, -

$129 \mathrm{OCH}_{3}$ in ethers, secondary amine group, esters such as $\mathrm{CH}_{3}-\mathrm{CO}-\mathrm{O}-$ and $-\mathrm{SO}_{3}$ of

130 hemicelluloses were observed between 1750 and $1047 \mathrm{~cm}^{-1}$. The FT-IR spectra in Figure 6

131 shows changes in surface properties and functional groups of the OS biomass after the

132 biosorption of ARS and MB, confirmed by the change in the peak heights and shifts of

133 functional group bands due to dyes biosorption.

134 The difference in the absorbance reading from 1 hour to 72 hours, although negative for ARS

135 but positive for MB, is very similar, indicating that almost the same number of dye molecules

136 are attached to the olive stone surface. The shifts and shape-changes occurring in the $-\mathrm{OH}$

137 stretching band at $3430 \mathrm{~cm}^{-1}$ shows that the dye is attached to the oxygen atoms creating

138 monodentate, bidentate or tridentate bonds and replacing the water molecules (Benjamin and

139 Leckie, 1981). This conclusion is in agreement with the previous findings for the molar ratio

140 between the biosorbed dye and $\mathrm{H}^{+}$released or adsorbed in section 3.3 and confirms that ARS

141 formed a tridentate complex whereas MB formed a monodentate complex with OS sites.

142 The topography of the olive stone before and after biosorption of ARS and MB are shown in

143 Figure 6. It is clear that the OS surface is non-homogeneous and rough with some visible pores

144 and fibre-like structures. These surface characteristics will provide an increase in the uptake

145 capacity of dye solution. After the biosorption of ARS and MB dyes, the OS surface is

146 smoother indicating that the dyes were densely and homogeneously adhered to the surface of

147 OS.

148 4. Conclusions

149 Raw biomass of olive stones was proven useful for biosorption of Alizarin Red S and 

ion exchange and chelation, were involved in the biosorption. ARS maximum capacity was found at $\mathrm{pH}=2$, whereas $\mathrm{MB}$ maximum capacity was obtained at $\mathrm{pH}=7.2$. it can be concluded that ARS and MB formed tridentate and monodentate complexes, respectively, with OS sites.

MB dye molecules.

\section{Acknowledgment}

160 The authors would like to thank Maria del Carmen Trujillo Miranda form University of

161 Granada, Spain, for facilitating the supply of the olive stone material.

\section{References}

The International Olive Council. Olivae. Off Mag Int Olive Counc. 2012.

164 Abdolali, A., Guo, W.S., Ngo, H.H., Chen, S.S., Nguyen, N.C., Tung, K.L., 2014. Typical

165 lignocellulosic wastes and by-products for biosorption process in water and wastewater 166 treatment: A critical review. Bioresource Technology 160, 57-66.

167 Ai, L., Zhou, Y., Jiang, J., 2011. Removal of methylene blue from aqueous solution by 168 montmorillonite/ $\mathrm{CoFe}_{2} \mathrm{O}_{4}$ composite with magnetic separation performance. Desalination 169 266, 72-77.

170 Albadarin, A.B., Mangwandi, C., Al-Muhtaseb, A.a.H., Walker, G.M., Allen, S.J., Ahmad, 171 M.N.M., 2012. Kinetic and thermodynamics of chromium ions adsorption onto low-cost 172 dolomite adsorbent. Chemical Engineering Journal 179, 193-202.

173 Albadarin, A.B., Mangwandi, C., Walker, G.M., Allen, S.J., Ahmad, M.N., 2011. Biosorption 174 characteristics of sawdust for the removal of Cd(II) Ions: Mechanism and thermodynamic studies. Chemical Engineering Transactions, 1297-1302. Albadarin, A.B., Mangwandi, C., Walker, G.M., Allen, S.J., Ahmad, M.N.M., Khraisheh, M., 2013. Influence of solution chemistry on $\mathrm{Cr}(\mathrm{VI})$ reduction and complexation onto date-pits/teawaste biomaterials. Journal of Environmental Management 114, 190-201.

Albadarin, A.B., Mo, J., Glocheux, Y., Allen, S., Walker, G., Mangwandi, C., 2014. Preliminary investigation of mixed adsorbents for the removal of copper and methylene blue from aqueous solutions. Chemical Engineering Journal 255, 525-534.

Banat, F., Al-Asheh, S., Al-Makhadmeh, L., 2003. Evaluation of the use of raw and activated date pits as potential adsorbents for dye containing waters. Process Biochemistry 39, 193-202. Benjamin, M.M., Leckie, J.O., 1981. Multiple-site adsorption of $\mathrm{Cd}, \mathrm{Cu}, \mathrm{Zn}$, and $\mathrm{Pb}$ on 
amorphous iron oxyhydroxide. Journal of Colloid and Interface Science 79, 209-221.

Bhattacharyya, K.G., Sharma, A., 2005. Kinetics and thermodynamics of Methylene Blue adsorption on Neem (Azadirachta indica) leaf powder. Dyes and Pigments 65, 51-59.

Blázquez, G., Calero, M., Ronda, A., Tenorio, G., Martín-Lara, M.A., 2014. Study of kinetics in the biosorption of lead onto native and chemically treated olive stone. Journal of Industrial and Engineering Chemistry 20, 2754-2760.

Boyd, G.E., Adamson, A.W., Myers Jr, L.S., 1947a. The exchange adsorption of ions from aqueous solution by organic zeolites II: Kinetics. Journal of the American Chemical Society 69, 2836-2848.

Boyd, G.E., Adamson, A.W., Myers, L.S., 1947b. The Exchange Adsorption of Ions from Aqueous Solutions by Organic Zeolites. II. Kinetics1. Journal of the American Chemical Society 69, 2836-2848.

Cao, J.-S., Lin, J.-X., Fang, F., Zhang, M.-T., Hu, Z.-R., 2014. A new absorbent by modifying walnut shell for the removal of anionic dye: Kinetic and thermodynamic studies. Bioresource Technology 163, 199-205.

Cuevas, M., Sánchez, S., García, J.F., Baeza, J., Parra, C., Freer, J., 2015. Enhanced ethanol production by simultaneous saccharification and fermentation of pretreated olive stones. Renewable Energy 74, 839-847.

Fu, F., Gao, Z., Gao, L., Li, D., 2011. Effective Adsorption of Anionic Dye, Alizarin Red S, from Aqueous Solutions on Activated Clay Modified by Iron Oxide. Industrial \& Engineering Chemistry Research 50, 9712-9717.

Galán, J., Rodríguez, A., Gómez, J.M., Allen, S.J., Walker, G.M., 2013. Reactive dye adsorption onto a novel mesoporous carbon. Chemical Engineering Journal 219, 62-68.

George Z. Kyzas, Nikolaos K. Lazaridis, Kostoglou, M., 2013. On the simultaneous adsorption of a reactive dye and hexavalent chromium from aqueous solutions onto grafted chitosan. Journal of Colloid and Interface Science 407, 432-441.

Ghaedi, M., Hassanzadeh, A., Kokhdan, S.N., 2011. Multiwalled carbon nanotubes as adsorbents for the kinetic and equilibrium study of the removal of Alizarin red S and morin. Journal of Chemical and Engineering Data 56, 2511-2520.

Glocheux, Y., Pasarín, M.M., Albadarin, A.B., Allen, S.J., Walker, G.M., 2013. Removal of arsenic from groundwater by adsorption onto an acidified laterite by-product. Chemical Engineering Journal 228, 565-574.

Gorgulu Ari, A., Celik, S., 2013. Biosorption potential of Orange G dye by modified Pyracantha coccinea: Batch and dynamic flow system applications. Chemical Engineering Journal 226, 263-270.

Guerrero-Coronilla, I., Morales-Barrera, L., Cristiani-Urbina, E., 2015. Kinetic, isotherm and thermodynamic studies of amaranth dye biosorption from aqueous solution onto water hyacinth leaves. Journal of Environmental Management 152, 99-108.

Guo, J.-Z., Li, B., Liu, L., Lv, K., 2014. Removal of methylene blue from aqueous solutions by chemically modified bamboo. Chemosphere 111, 225-231.

Gürses, A., Doğar, Ç., Yalçın, M., Açıkyıldız, M., Bayrak, R., Karaca, S., 2006. The adsorption kinetics of the cationic dye, methylene blue, onto clay. Journal of Hazardous Materials 131, 217-228.

Ho, Y.S., McKay, G., 1999. Pseudo-second order model for sorption processes. Process Biochemistry 34, 451-465.

Janoš, P., Buchtová, H., Rýznarová, M., 2003. Sorption of dyes from aqueous solutions onto fly ash. Water Research 37, 4938-4944.

Kabbout, R., Taha, S., 2014. Biodecolorization of Textile Dye Effluent by Biosorption on Fungal Biomass Materials. Physics Procedia 55, 437-444.

Khataee, A.R., Vafaei, F., Jannatkhah, M., 2013. Biosorption of three textile dyes from 
contaminated water by filamentous green algal Spirogyra sp.: Kinetic, isotherm and thermodynamic studies. International Biodeterioration \& Biodegradation 83, 33-40. Lagergren, S., 1898. Zur theorie der sogenannten adsorption gelöster stoffe KungligaSvenska Vetenskapsakademiens, Handlingar 24, 1-39. Liao, P., Malik Ismael, Z., Zhang, W., Yuan, S., Tong, M., Wang, K., Bao, J., 2012. Adsorption of dyes from aqueous solutions by microwave modified bamboo charcoal. Chemical Engineering Journal 195-196, 339-346. dyes by lignocellulose adsorbents originating from biodiesel production. Journal of Environmental Chemical Engineering 2, 2199-2210. Olivier Thomas, Burgess, C., 2007. UV-visible Spectrophotometry of Water and Wastewater. Elsevier. anionic and cationic dyes on ferromagnetic ordered mesoporous carbon from aqueous solution: Equilibrium, thermodynamic and kinetics. Journal of Colloid and Interface Science 430, 272282.

Redlich, O., Peterson, D.L., 1959. A Useful Adsorption Isotherm. The Journal of Physical Chemistry 63, 1024-1024.

Ronda, A., Martín-Lara, M.A., Calero, M., Blázquez, G., 2013. Analysis of the kinetics of lead biosorption using native and chemically treated olive tree pruning. Ecological Engineering 58, 278-285.

Roosta, M., Ghaedi, M., Mohammadi, M., 2014. Removal of Alizarin Red S by gold nanoparticles loaded on activated carbon combined with ultrasound device: Optimization by experimental design methodology. Powder Technology 267, 134-144.

Semeraro, P., Rizzi, V., Fini, P., Matera, S., Cosma, P., Franco, E., García, R., Ferrándiz, M., Núñez, E., Gabaldón, J.A., Fortea, I., Pérez, E., Ferrándiz, M., 2015. Interaction between industrial textile dyes and cyclodextrins. Dyes and Pigments 119, 84-94.

Silvina Pirillo, María Luján Ferreiraa, Ruedaa, E.H., 2009. The effect of pH in the adsorption of Alizarin and Eriochrome Blue Black R onto iron oxides. Journal of Hazardous Materials 168, 168-178.

Sun, J., Lu, H., Du, L., Lin, H., Li, H., 2011. Anodic oxidation of anthraquinone dye Alizarin Red S at Ti/BDD electrodes. Applied Surface Science 257, 6667-6671.

Tavlieva, M.P., Genieva, S.D., Georgieva, V.G., Vlaev, L.T., 2013. Kinetic study of brilliant green adsorption from aqueous solution onto white rice husk ash. Journal of Colloid and Interface Science 409, 112-122.

Temkin, M., Levich, V., 1946. Adsorption equilibrium on heterogeneous surfaces. Journal of Physical Chemistry 20, 1441-1457.

Valentina Hernández, Juan M. Romero-García, Javier A. Dávila, Eulogio Castro, Cardona, C.A., 2014. Techno-economic and environmental assessment of an olive stonebased biorefinery. Resources, Conservation and Recycling 92, 145-150.

Wang, M.-X., Zhang, Q.-L., Yao, S.-J., 2015. A novel biosorbent formed of marine-derived Penicillium janthinellum mycelial pellets for removing dyes from dye-containing wastewater. Chemical Engineering Journal 259, 837-844.

Weber, W.J., Morris, J.C., 1963. Kinetics of adsorption on carbon from solution. J. Sanity Eng. Div. American Society of Civil Engineering 89, 31-59.

Weifeng Liu, Jian Zhang, Cheng Cheng, Guipeng Tian, Zhang, C., 2011. Ultrasonic-assisted sodium hypochlorite oxidation of activated carbons for enhanced removal of $\mathrm{Co}$ (II) from aqueous solutions. Chemical Engineering Journal 175, 24-32.

Wouter Delée, Cliona O'Neill, Freda R. Hawkes, Pinheiro, H.M., 1998. Anaerobic treatment of textile effluents: A review. Journal of Chemical Technology and Biotechnology 73, 323-335. 
285 Wu, Z., Ahn, I.-S., Lee, C.-H., Kim, J.-H., Shul, Y.G., Lee, K., 2004. Enhancing the organic 286 dye adsorption on porous xerogels. Colloids and Surfaces A: Physicochemical and Engineering 287 Aspects 240, 157-164.

288 Zhang, J., Li, J.-n., Deng, P.-h., 2001. Adsorption voltammetry of the scandium-alizarin red S 289 complex onto a carbon paste electrode. Talanta 54, 561-566. 

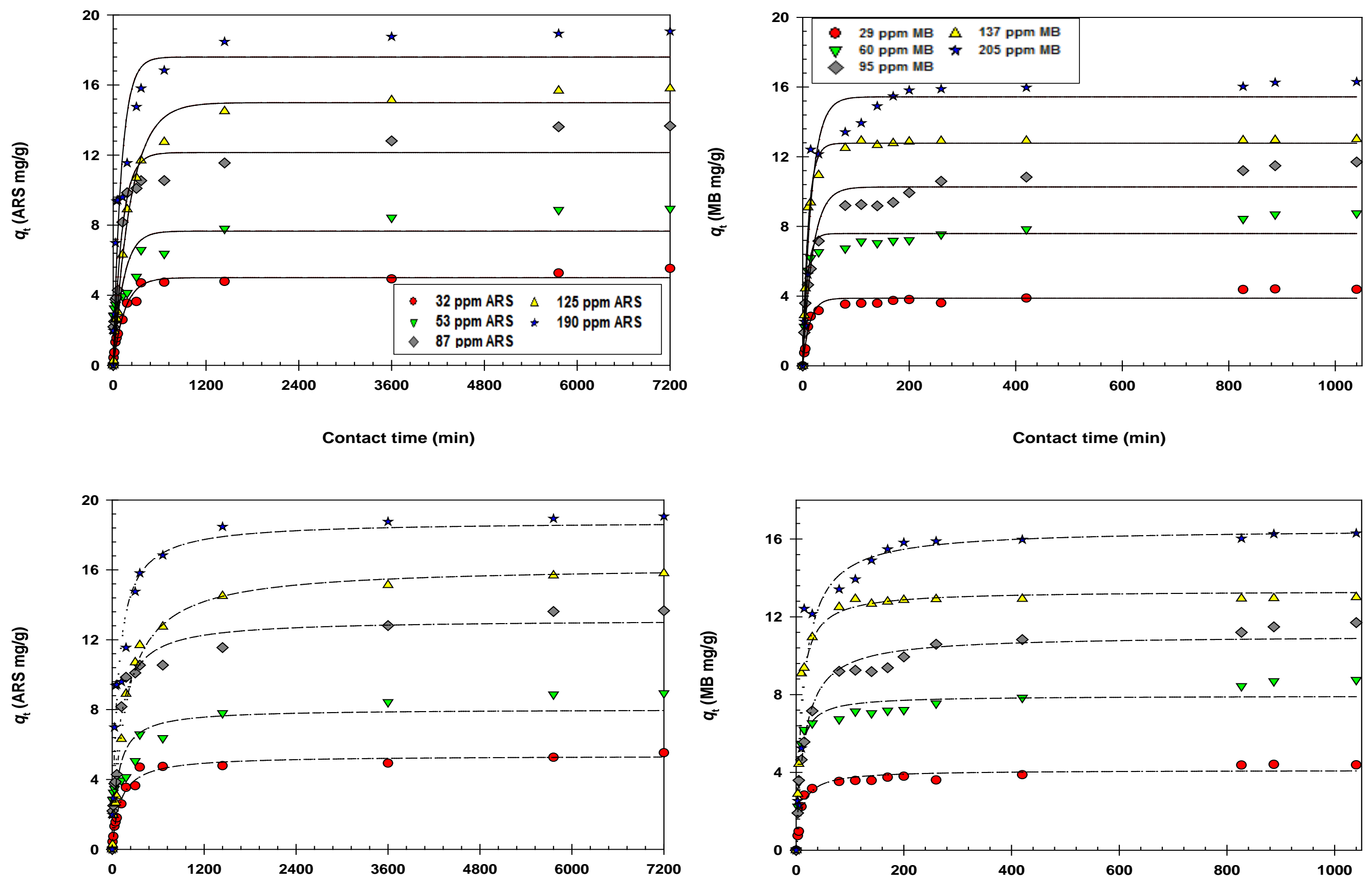
Figure 1: The fitting of pseudo first- (continuous line), second-order (short-dash line) models.
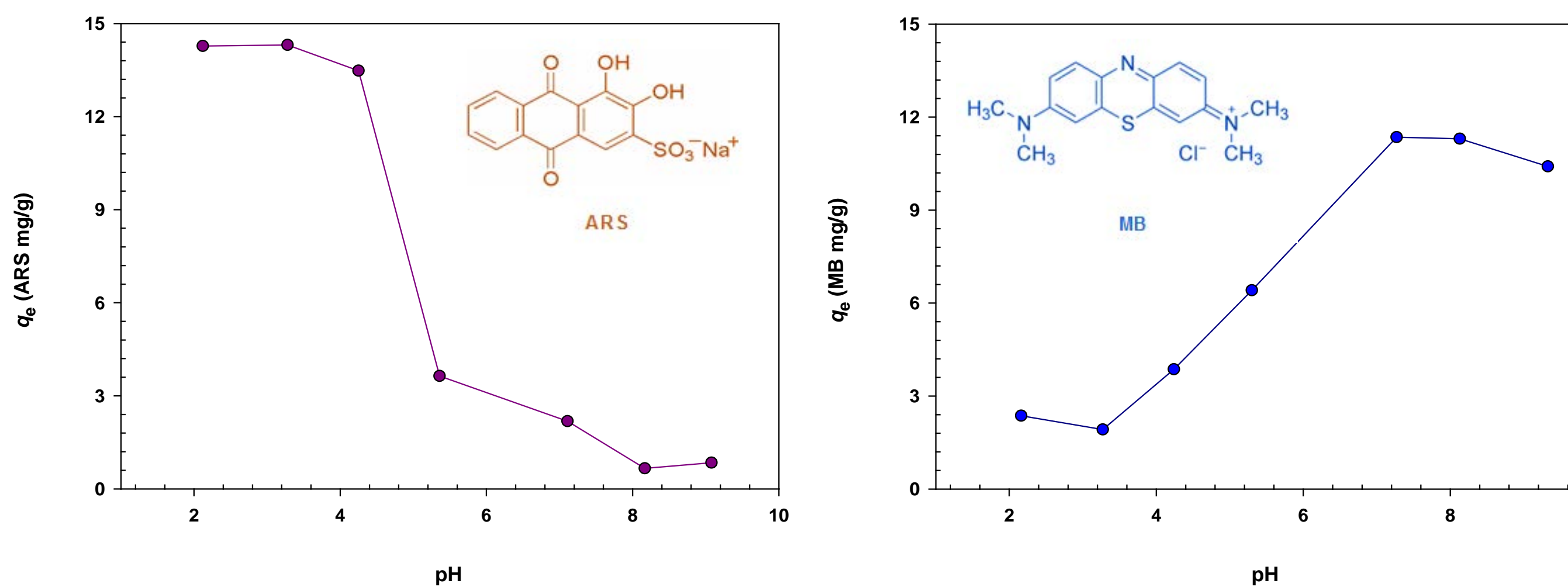

Figure 2: Biosorption of Alizarin Red S (ARS) and Methylene Blue (MB) onto olives stone as a function of pH. Experimental conditions: $C_{0}=110 \mathrm{mg} / \mathrm{dm}^{3}$; volume $25 \mathrm{~cm}^{3}$; biosorbent dosage $5.0 \mathrm{~g} / \mathrm{dm}^{3}$; and shaking speed $100 \mathrm{rpm}$ for $72 \mathrm{hrs}$. 


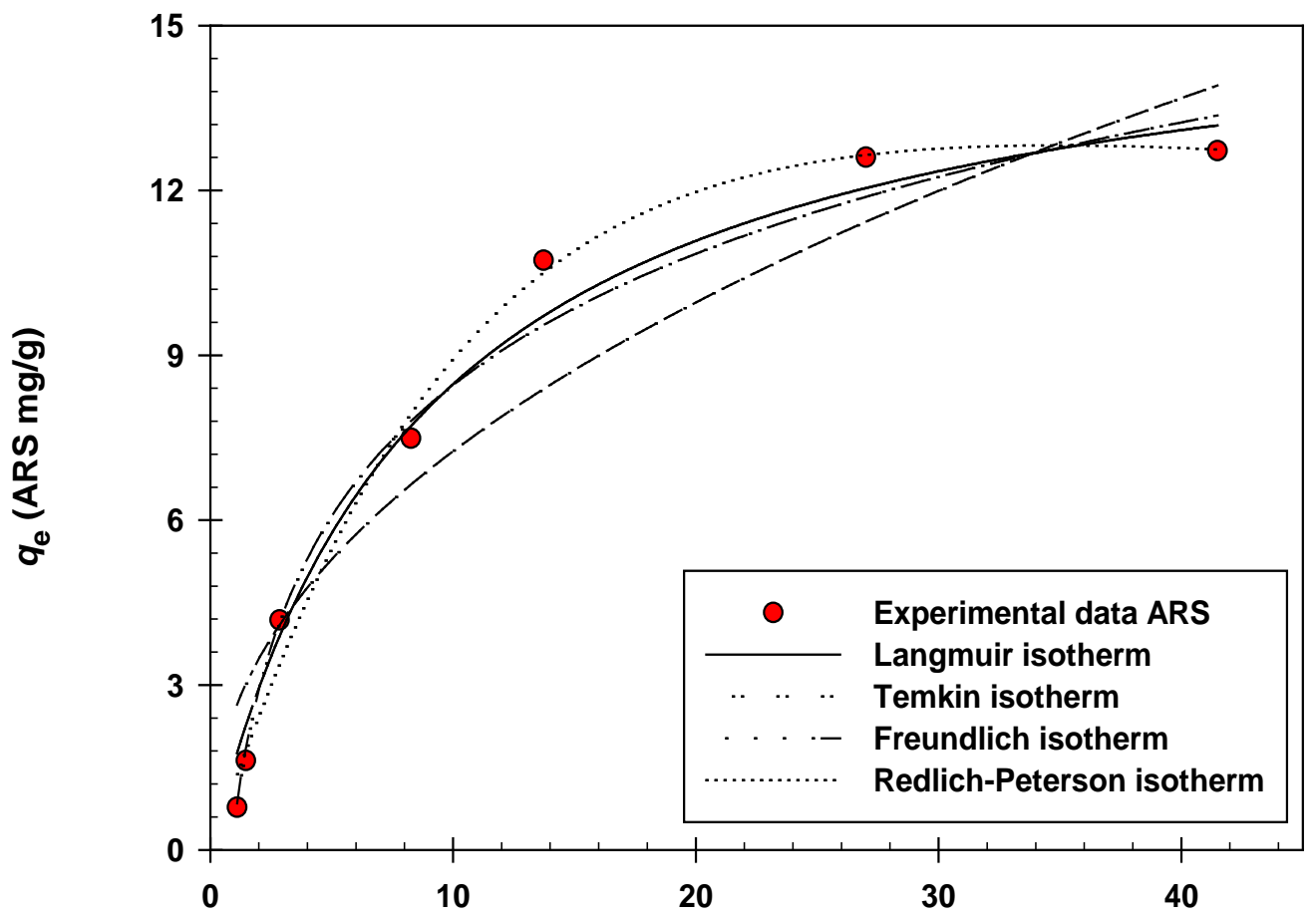

Equilibrium concentration $\left(\mathrm{mg} / \mathrm{dm}^{3}\right)$ 


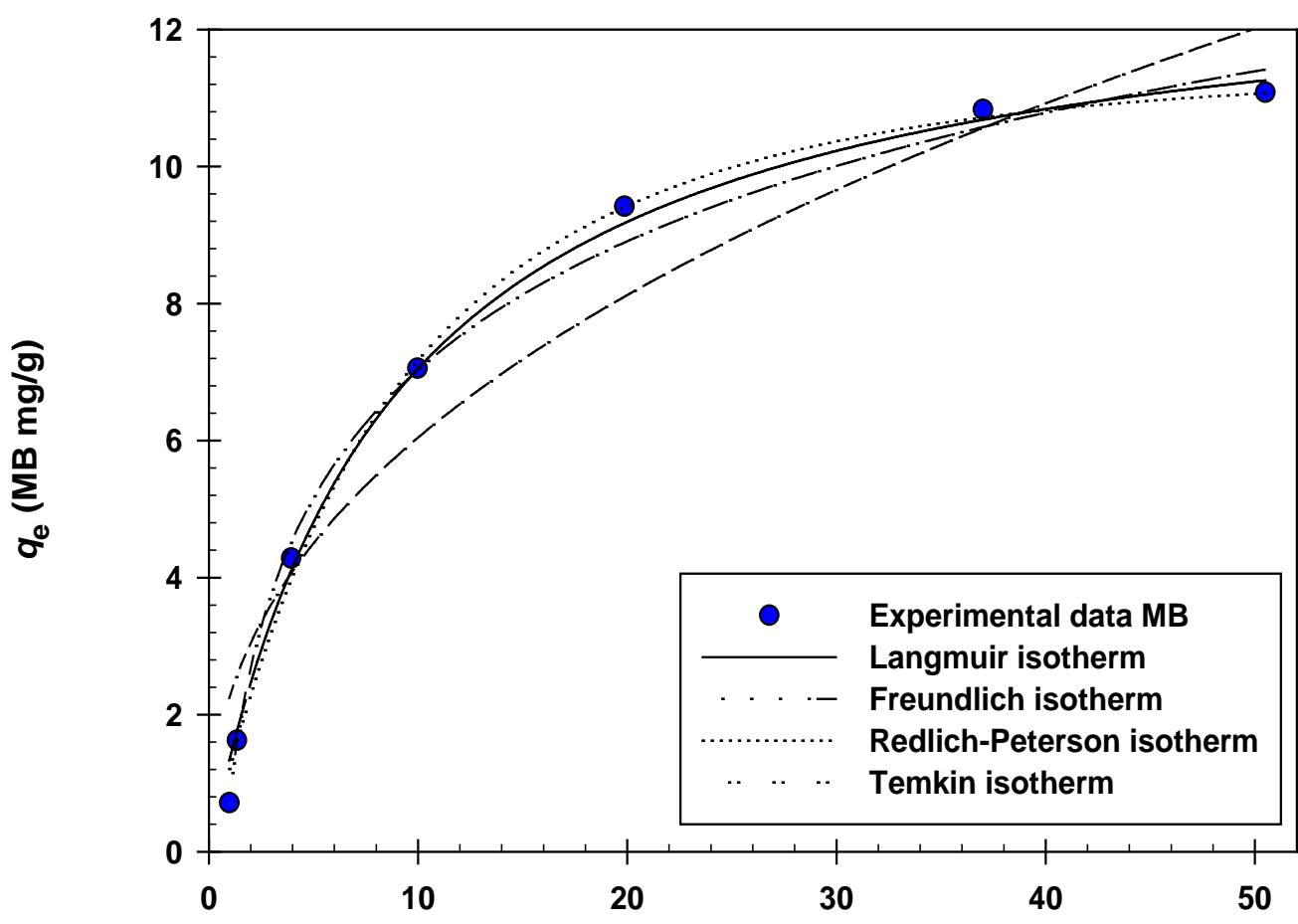

Equilibrium concentration $\left(\mathrm{mg} / \mathrm{dm}^{3}\right)$

Figure 3: Non-linear forms of biosorption isotherm plots for ARS and MB biosorption onto OS. 


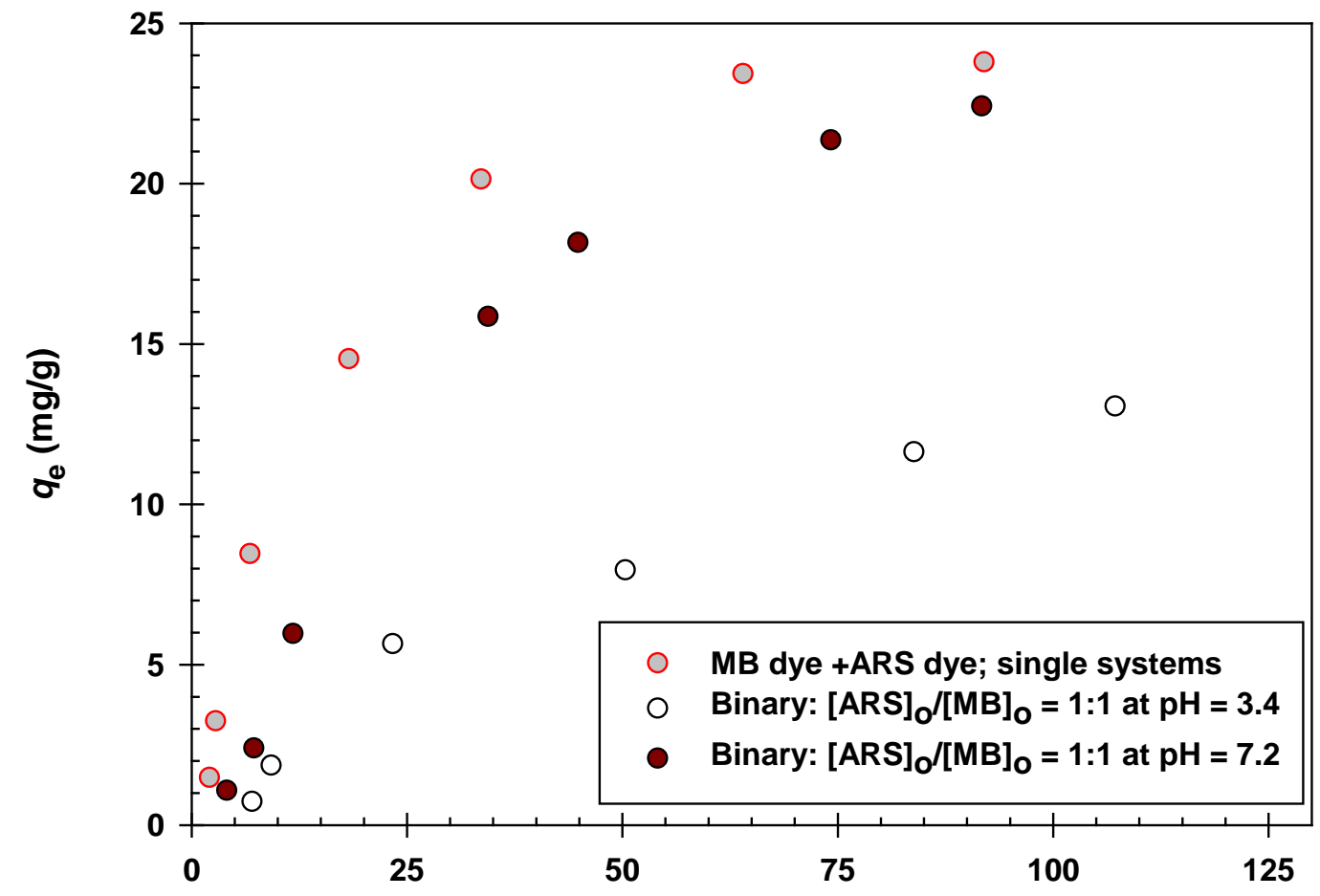

Equilibrium concentration $\left(\mathrm{mg} / \mathrm{dm}^{3}\right)$ 


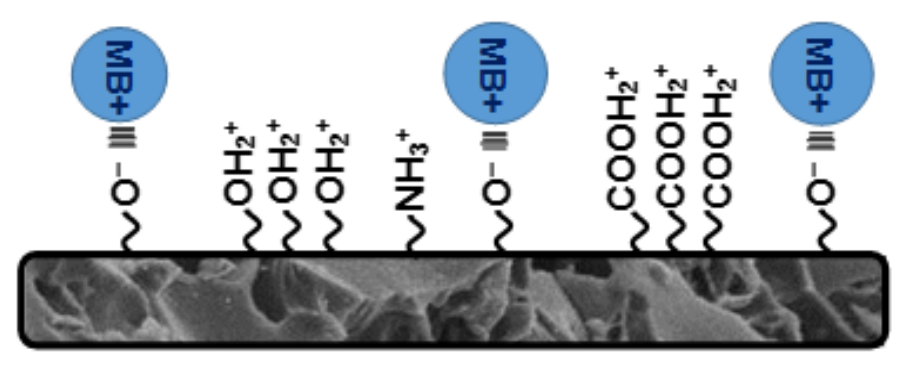

Irreversible equilibrium scenario: ARS molecules can be bound only to unoccupied sites
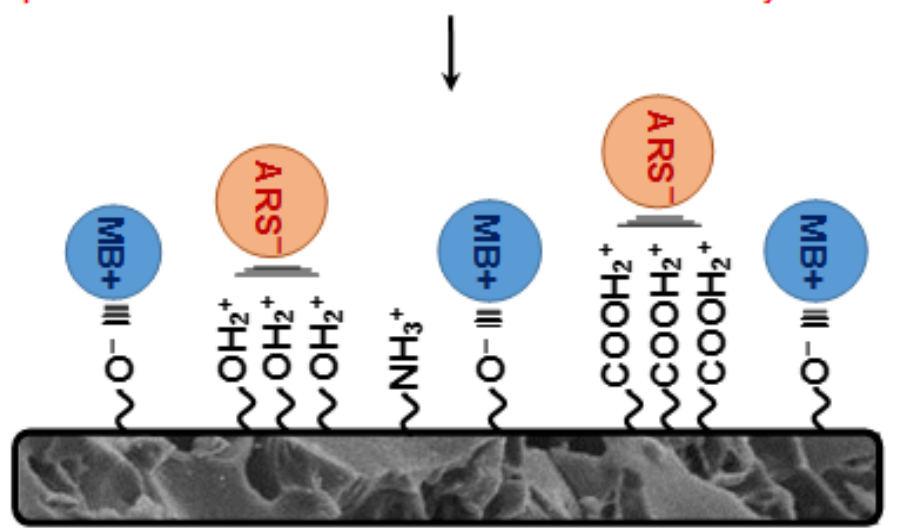

Figure 4: Comparison between total $C_{\mathrm{e}} v s$ total $q_{\mathrm{e}}$ at various $\mathrm{pH}$ for ARS and MB biosorption in single and binary mixture: $\left(q_{\mathrm{e}}=q_{\mathrm{e}, \mathrm{ARS}}+q_{\mathrm{e}, \mathrm{MB}}\right)$ and $\left(C_{\mathrm{e}}=\right.$ $\left.C_{\mathrm{e}, \mathrm{ARS}}+C_{\mathrm{e}, \mathrm{MB}}\right)$ and proposed irreversible equilibrium scenario for the biosorption of ARS and MB onto OS in binary system. 


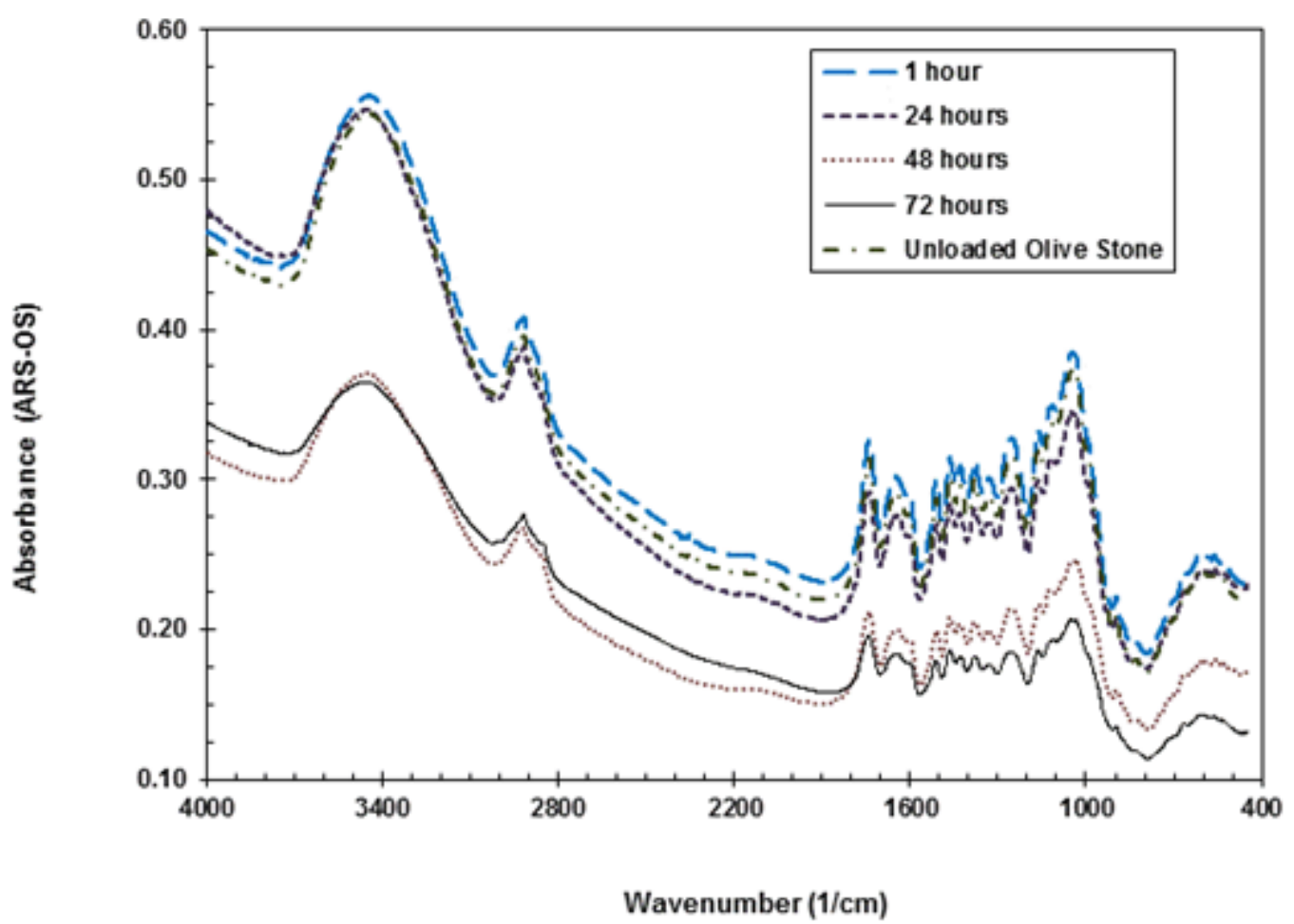




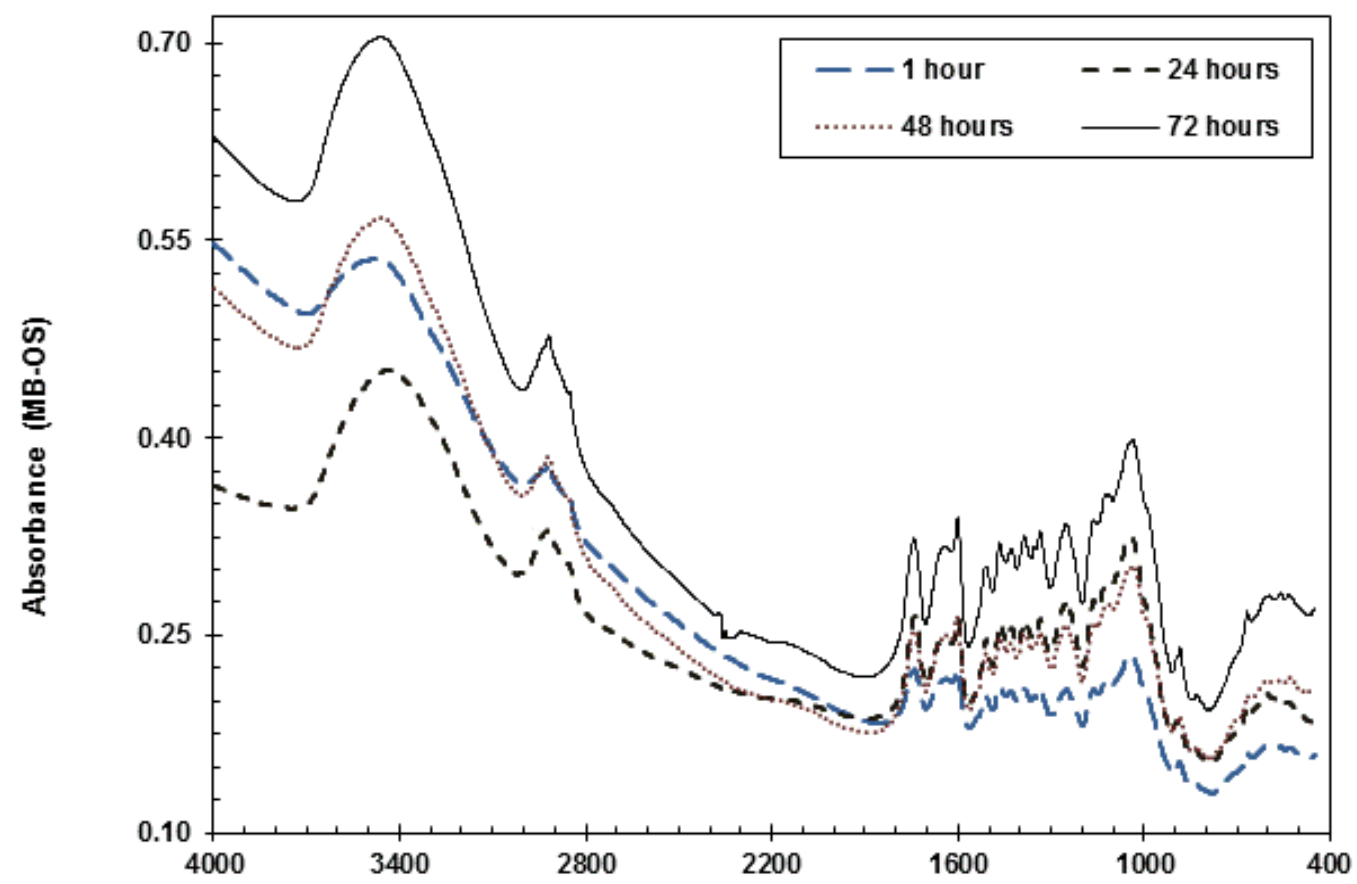

5ourier transform infrared (FT-IR) spectroscopy spectra of -unloaded olive stone (OS) and Alizarin Red S- (ARS-OS) and Methylene Blue-loaded olive stone (MB-OS). 


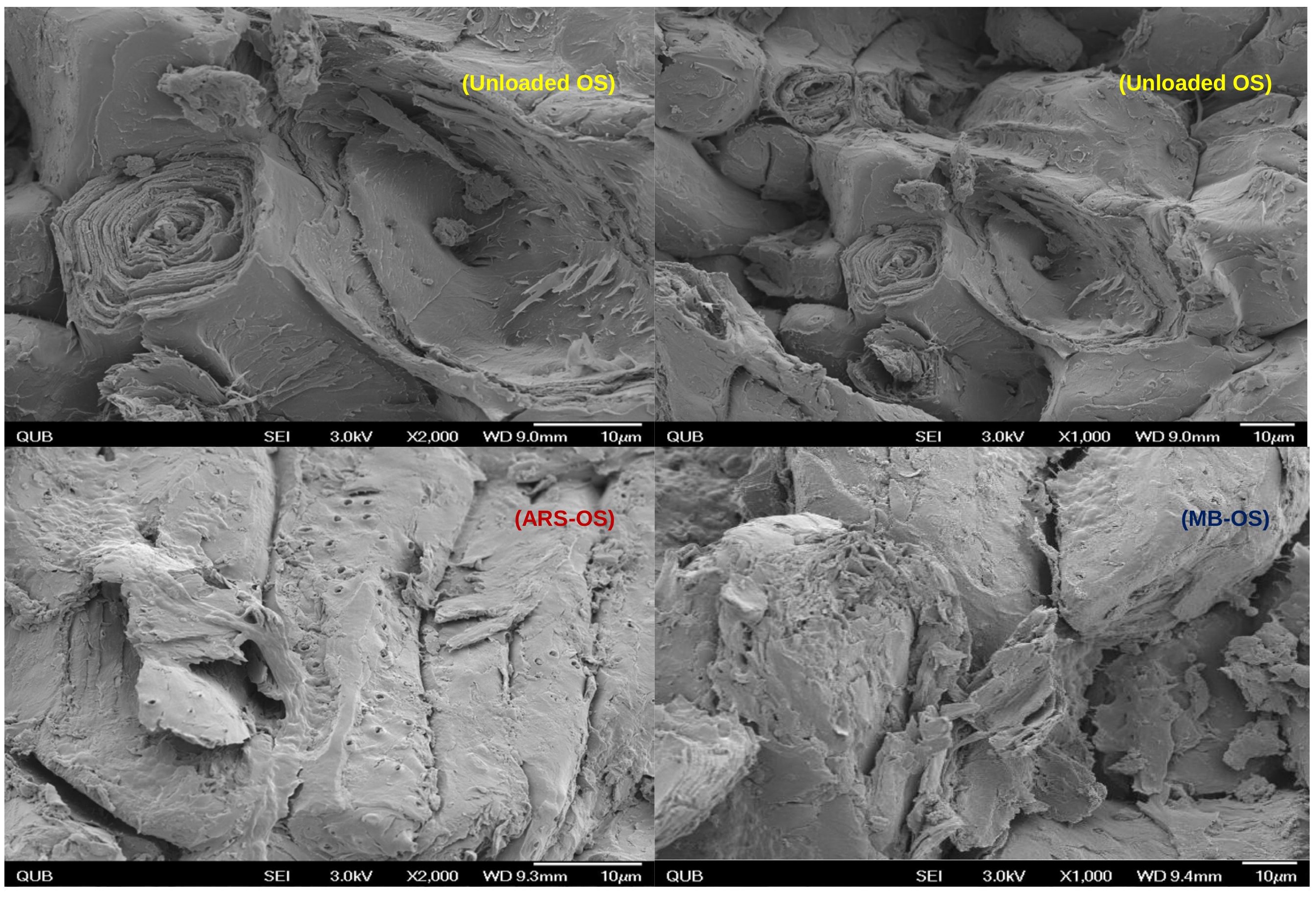


331

332

333

Figure 6: Scanning electron microscopy of unloaded olive stone and ARS- and MB-loaded olive stone. 
334 Table 1: Pseudo first-order and pseudo second-order model constants for ARS and MB

335 biosorption onto olive stone.

\begin{tabular}{lllllllll}
\hline & \multicolumn{3}{c}{$\boldsymbol{C}_{\mathbf{0}}$} & \multicolumn{3}{c}{ Pseudo first-order model } & \multicolumn{3}{c}{ Pseudo second-order model } \\
\hline & & $q_{\mathrm{e}, \mathrm{exp}}$ & $q_{\mathrm{e}, \mathrm{cal}}$ & $k_{1}$ & $R^{2}$ & $q_{\mathrm{e}, \mathrm{cal}}$ & $k_{2}$ & $R^{2}$ \\
& $(\mathrm{mg} / \mathrm{g})$ & $(\mathrm{mg} / \mathrm{g})$ & $(1 / \mathrm{min})$ & & $(\mathrm{mg} / \mathrm{g})$ & $(\mathrm{g} / \mathrm{mg} \mathrm{min})$ & \\
\hline & $\mathbf{3 2}\left(\mathbf{m g} / \mathbf{d m}^{3}\right)$ & 5.531 & 5.008 & 0.008 & 0.987 & 5.363 & $1.80 \times 10^{3}$ & 0.992 \\
& $\mathbf{5 3}\left(\mathbf{m g} / \mathbf{d m}^{3}\right)$ & 8.942 & 7.669 & 0.007 & 0.819 & 8.030 & $1.70 \times 10^{3}$ & 0.910 \\
$\mathbf{A R S}$ & $\mathbf{8 7}\left(\mathbf{m g} / \mathbf{d m}^{3}\right)$ & 13.66 & 12.15 & 0.008 & 0.973 & 13.14 & $0.90 \times 10^{3}$ & 0.986 \\
& $\mathbf{1 2 5}\left(\mathbf{m g} / \mathbf{d m}^{3}\right)$ & 15.81 & 15.00 & 0.004 & 0.991 & 16.21 & $0.40 \times 10^{3}$ & 0.997 \\
& $\mathbf{1 9 0}\left(\mathbf{m g} / \mathbf{d m}^{3}\right)$ & 19.06 & 17.61 & 0.009 & 0.959 & 18.78 & $0.30 \times 10^{3}$ & 0.986 \\
\hline & $\mathbf{2 9}\left(\mathbf{m g} / \mathbf{d m}^{3}\right)$ & 4.381 & 3.878 & 0.074 & 0.974 & 4.117 & 0.023 & 0.982 \\
& $\mathbf{6 0}\left(\mathbf{m g} / \mathbf{d m}^{3}\right)$ & 8.750 & 7.588 & 0.117 & 0.967 & 7.938 & 0.021 & 0.978 \\
$\mathbf{M B}$ & $\mathbf{9 5}\left(\mathbf{m g} / \mathbf{d m}^{3}\right)$ & 11.70 & 10.26 & 0.053 & 0.970 & 11.03 & 0.006 & 0.991 \\
& $\mathbf{1 3 7}\left(\mathbf{m g} / \mathbf{d m}^{3}\right)$ & 13.01 & 12.77 & 0.094 & 0.990 & 13.33 & 0.001 & 0.996 \\
\hline $\mathbf{2 0 5}\left(\mathbf{m g} / \mathbf{d m}^{3}\right)$ & 16.30 & 15.43 & 0.059 & 0.974 & 16.50 & 0.001 & 0.975 \\
\hline
\end{tabular}

336

337

338

339

340

341

342

343

344

345

346

347 
349 Table 2: Intraparticle diffusion model parameters for the different diffusion phase

\begin{tabular}{|c|c|c|c|c|c|c|c|}
\hline & \multirow[t]{2}{*}{$C_{\mathrm{o}}$} & \multicolumn{6}{|c|}{ Intraparticle diffusion coefficients in $\mathrm{mg} / \mathrm{g} . \mathrm{h}^{0.5}$} \\
\hline & & $k_{\mathrm{d} 1}$ & $R^{2}$ & $k_{\mathrm{d} 2}$ & $R^{2}$ & $k_{\mathrm{d} 3}$ & $R^{2}$ \\
\hline \multirow{5}{*}{ ARS } & $32\left(\mathrm{mg} / \mathrm{dm}^{3}\right)$ & 0.280 & 0.990 & 0.017 & 0.671 & - & - \\
\hline & $53\left(\mathrm{mg} / \mathrm{dm}^{3}\right)$ & 0.159 & 0.870 & 0.025 & 0.971 & - & - \\
\hline & $87\left(\mathrm{mg} / \mathbf{d m}^{3}\right)$ & 0.802 & 0.963 & 0.054 & 0.960 & - & - \\
\hline & $125\left(\mathrm{mg} / \mathrm{dm}^{3}\right)$ & 0.557 & 0.892 & 0.703 & 0.979 & 0.046 & 0.868 \\
\hline & $190\left(\mathrm{mg} / \mathrm{dm}^{3}\right)$ & 2.969 & 0.874 & 0.697 & 0.981 & 0.031 & 0.727 \\
\hline \multirow{5}{*}{ MB } & $29\left(\mathrm{mg} / \mathrm{dm}^{3}\right)$ & 1.039 & 0.979 & 0.046 & 0.893 & 0.003 & 0.991 \\
\hline & $60\left(\mathrm{mg} / \mathrm{dm}^{3}\right)$ & 2.224 & 0.990 & 0.089 & 0.973 & 0.051 & 1.000 \\
\hline & $95\left(\mathrm{mg} / \mathrm{dm}^{3}\right)$ & 1.315 & 0.953 & 0.193 & 0.777 & 0.070 & 0.907 \\
\hline & $137\left(\mathrm{mg} / \mathrm{dm}^{3}\right)$ & 4.353 & 0.987 & 0.883 & 0.990 & 0.013 & 0.510 \\
\hline & $205\left(\mathrm{mg} / \mathrm{dm}^{3}\right)$ & 0.463 & 1.000 & 10.09 & 0.982 & 0.118 & 0.606 \\
\hline
\end{tabular}

350

351

352

353

354

355

356

357

358

359

360 
361 Table 3: The Langmuir, Freundlich, Redlich-Peterson and Temkin parameters and correlation

362 coefficients for ARS and MB dyes biosorption onto olive stone.

\begin{tabular}{|c|c|c|c|}
\hline Model & Parameters & ARS & MB \\
\hline Langmuir isotherm & $q_{\max }(\mathrm{mg} / \mathrm{g})$ & 16.10 & 13.20 \\
\hline \multirow{2}{*}{$q_{e}=\frac{q_{\max } b C_{e}}{1+b C_{e}}$} & $b\left(\mathrm{dm}^{3} / \mathrm{mg}\right)$ & 0.112 & 0.115 \\
\hline & $R_{\mathrm{adj}^{2}}$ & 0.988 & 0.995 \\
\hline Freundlich isotherm & $K_{F}\left(\mathrm{mg} / \mathrm{g}\left(\mathrm{dm}^{3} / \mathrm{mg}\right)^{1 / \mathrm{n}}\right)$ & 2.529 & 2.262 \\
\hline \multirow{2}{*}{$q_{e}=K_{F} C_{e}^{1 / n}$} & $1 / n$ & 0.457 & 0.426 \\
\hline & $R_{\mathrm{adj}^{2}}$ & 0.944 & 0.959 \\
\hline Redlich-Peterson isotherm & $K_{R}\left(\mathrm{dm}^{3} / \mathrm{mg}\right)$ & 1.273 & 1.306 \\
\hline \multirow{3}{*}{$q_{e}=\frac{K_{R} C_{e}}{1+a_{R} C_{e}^{\beta}}$} & $a_{R}\left(\left(\mathrm{dm}^{3} / \mathrm{mg}\right)^{1 / \beta}\right)$ & 0.016 & 0.063 \\
\hline & $B$ & 1.407 & 1.101 \\
\hline & $R_{\mathrm{adj}^{2}}$ & 0.994 & 0.998 \\
\hline Temkin isotherm & $A_{\mathrm{T}}\left(\mathrm{dm}^{3} / \mathrm{g}\right)$ & 1.163 & 1.342 \\
\hline \multirow{2}{*}{$q_{e}=\frac{R T}{b_{T}} \ln A_{T} C_{e}$} & $b_{\mathrm{T}}$ & 706.7 & 899.3 \\
\hline & $R_{\mathrm{adj}^{2}}$ & 0.992 & 0.995 \\
\hline
\end{tabular}

363

364

365

366

367

368

369

370 
371 Table 4: Comparison of Langmuir biosorption capacities of ARS and MB with results from previous

372 studies.

\begin{tabular}{|c|c|c|c|}
\hline \multirow[t]{2}{*}{ Material } & \multicolumn{2}{|c|}{ Adsorbate } & \multirow[t]{2}{*}{ Reference } \\
\hline & ARS $[\mathrm{mg} / \mathrm{g}]$ & $\mathrm{MB}[\mathrm{mg} / \mathrm{g}]$ & \\
\hline Olive Stone & 16.01 & 13.20 & This work \\
\hline Teawaste \& Dolomite & - & 150.0 & (Albadarin et al., 2014) \\
\hline Clay & - & 58.20 & (Gürses et al., 2006) \\
\hline $\begin{array}{l}\text { Activated clay modified } \\
\text { by iron oxide }\end{array}$ & 32.70 & - & (Fu et al., 2011) \\
\hline Silica & & 11.21 & (Janoš et al., 2003) \\
\hline M-MCCNT & & 48.08 & (Ai et al., 2011) \\
\hline $\begin{array}{l}\mathrm{MMT} / \mathrm{CoFe}_{2} \mathrm{O}_{4} \\
\text { composite }\end{array}$ & & 97.75 & (Ai et al., 2011) \\
\hline Raw date pits & & 27.27 & (Banat et al., 2003) \\
\hline Activate Date pits & & 80.29 & (Banat et al., 2003) \\
\hline Porous Xerogels & $8.30 \mathrm{mmol} / \mathrm{kg}$ & - & (Wu et al., 2004) \\
\hline MWCNT & 161.3 & - & (Ghaedi et al., 2011) \\
\hline
\end{tabular}


376
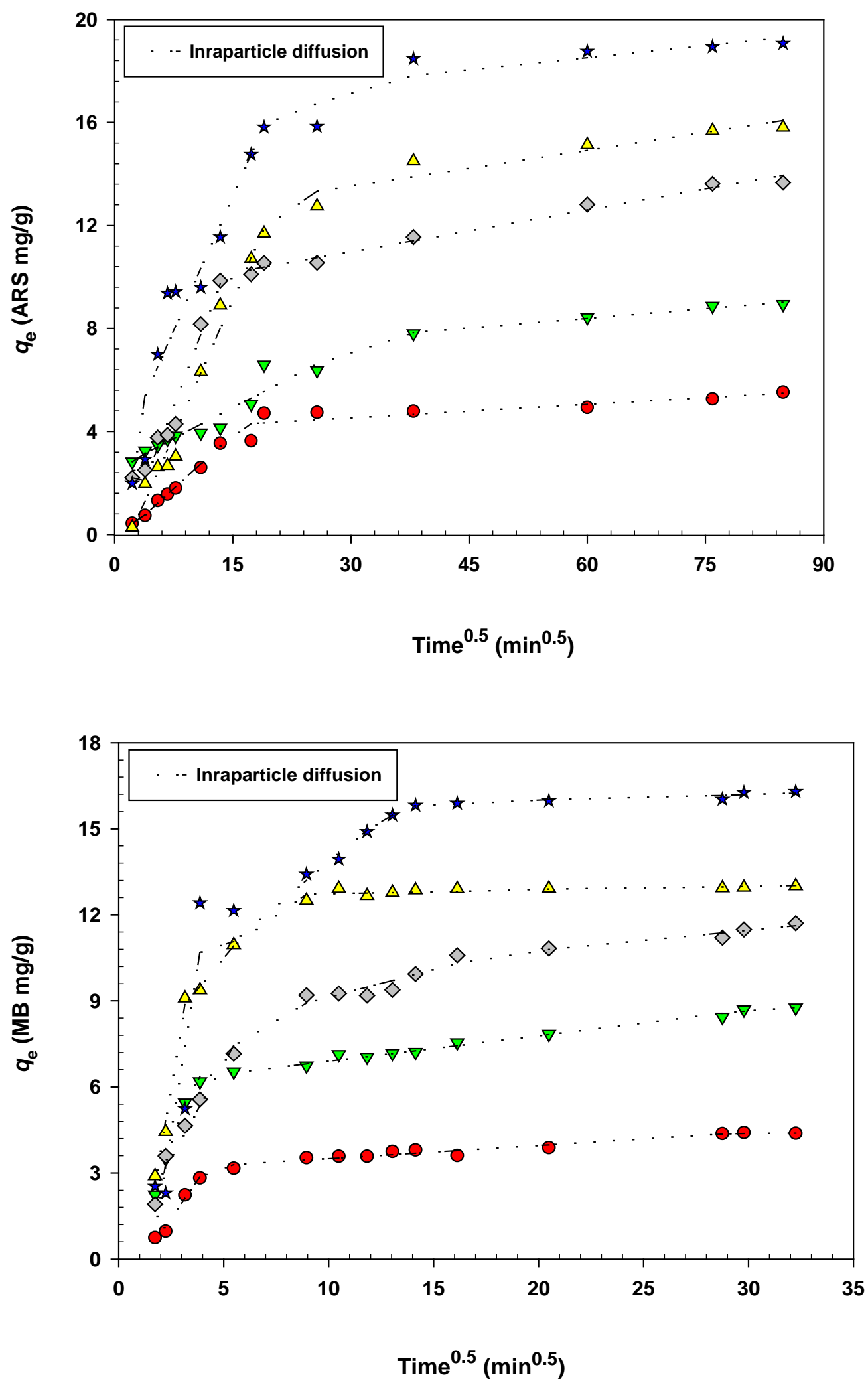
380 Figure S1: Intraparticle diffusion model (time ${ }^{0.5} v s$ e plots) for ARS and MB biosorption onto OS.

381

382 